\section{Using Logistic Regression to Predict the Probability That Individual 'Honeycrisp' Apples Will Develop Bitter Pit}

\author{
Richard P. Marini \\ Department of Plant Science, The Pennsylvania State University, 203 Tyson \\ Building, University Park, PA 16802
}

Emily K. Lavely

Department of Plant Science, The Pennsylvania State University, 207 Forestry Resources Building, University Park, PA 16802

Tara Auxt Baugher

The Pennsylvania State University, Cooperative Extension in Adams County, 670 Old Harrisburg Road, Gettysburg, PA 17325

\author{
Robert Crassweller \\ Department of Plant Science, The Pennsylvania State University, 119 Tyson \\ Building, University Park, PA 16802
}

\section{James R. Schupp \\ Fruit Research and Extension Center, The Pennsylvania State University, 290 University Drive, Biglerville, PA 17307}

Additional index words. binary analysis, bourse shoots, calcium disorders, canopy position, fruit weight, Malus $\times$ domestica, ROC curves, spur characteristics

\begin{abstract}
Honeycrisp' is a popular apple cultivar, but it is prone to several disorders, especially bitter pit. Previously reported models for predicting bitter pit are biased, indicating that the models are missing one or more important predictor variables. To identify additional variables that may improve bitter pit prediction, a study was undertaken to investigate the influence of canopy position, spur characteristics, and individual fruit characteristics on bitter pit development. 'Honeycrisp' trees from two orchards over 2 years provided four combinations of orchards and years. Fruits were sampled from spurs at different canopy positions and with varying bourse shoot lengths and numbers of fruits and leaves. Following cold storage, bitter pit was assessed in three ways: 1) bitter pit severity was recorded as the number of pits per fruit, 2) bitter pit was recorded as a binomial response (yes, no) for each fruit, and 3) the incidence of bitter pit was recorded as the proportion of fruit developing bitter pit. As a result of the high fruit-to-fruit variation, bitter pit severity was associated with canopy position or spur characteristics to a lesser extent than bitter pit incidence. Bitter pit incidence was generally greater for fruits developing on spurs with only one fruit and spurs from the lower canopy. Binomial data were analyzed with a generalized linear mixed model. Fruit harvested from trees with heavy crop loads, and those developing on spurs with multiple fruit and spurs with long bourse shoots had the lowest probability of developing bitter pit. Regardless of how bitter pit was assessed, bitter pit related positively to fruit weight (FW), but the relationship usually depended on other variables such as canopy position, fruit per spur, and leaves per spur. The advantages of fitting binomial data with logistic regression models are discussed.
\end{abstract}

'Honeycrisp' is one of the top five apple cultivars in the United States, but consistent production of high-quality fruit is challenging. One negative characteristic of the cultivar is its susceptibility to bitter pit. The severity of bitter pit varies across years, orchards, and trees within orchards. For example, the incidence of bitter pit for individual trees within an orchard varied from $0 \%$ to $100 \%$, and bitter pit for a given tree may vary with crop load and tree vigor (Baugher et al., 2017).

In commercial apple production, accurate predictions of bitter pit incidence are critical to provide high-quality fruit to consumers. Understanding which fruit on a tree are most likely to develop bitter pit has implications for management practices and postharvest strategies. For example, if growers could identify fruit with a high likelihood of bitter pit development, they could sell those fruit immediately, whereas fruit with a low likelihood of bitter pit development could be stored. To predict bitter pit incidence, researchers have used preharvest fruit mineral analysis to identify blocks of trees that are likely to have a high incidence of bitter pit after storage (Baugher et al., 2017; Perring, 1986; Torres et al., 2017). More recently Al Shoffe et al. (2019) evaluated a nonmineral prediction method.

However, these predictive models explained no more than $70 \%$ of the variation in observed bitter pit incidence. Some models are biased because they tend to underpredict the incidence of bitter pit for orchards with a high observed incidence of bitter pit (Al Shoffe et al., 2019; Baugher et al., 2017). The poor predictive ability and the biased nature of these models indicates that one or more important variables associated with bitter pit have yet to be identified.

High variability in bitter pit incidence within a tree may be a result of multiple factors that affect nutrient transport to the fruit, such as nutrient availability and transpiration. For example, bitter pit is associated with low concentrations of calcium and high ratios of nitrogen and cations to calcium in apple fruit flesh and peel tissue (Baugher et al., 2017; Cheng and Sazo, 2018; Ferguson, 2001; Ferguson and Watkins, 1989). Calcium moves with the transpiration stream and enters the fruit through the xylem (Tromp and Oele, 1972). Therefore, fruit developing on spurs with high transpiration rates would likely have a high calcium content and a low incidence of bitter pit. However, the relationship between transpiration, calcium availability, and bitter pit is complex. For example, several tree and environmental factors influence transpiration and fruit mineral concentration, such as crop density (Ferguson and Watkins, 1992), fruit size (Perring and Jackson, 1975), shade (Jackson and Sharples, 1971), temperature (Tromp, 1974), humidity (Cline and Hanson, 1992; Tromp and Oele, 1972), fruit maturity (Prange et al., 2015), the presence of bourse shoots, and leaf area per spur (Volz et al., 1994).

In addition to transpiration, tree canopy position influences the microclimate around a fruit, and can affect fruit maturity and quality (Feng et al., 2014; Krishnaprakash et al., 1983; Tustin et al., 1988). Leaves and fruit in the lower shaded region of the canopy likely have low transpiration rates, resulting in low fruit calcium concentrations and a greater likelihood of developing bitter pit. However, there are conflicting reports concerning the influence of fruit position within a canopy on fruit calcium and bitter pit. Jackson and Sharples (1971) and Ferguson and Triggs (1990) found lower calcium concentrations in fruit from the upper canopy. To the contrary, Kalcsits et al. (2019) reported greater concentrations of calcium and a lower incidence of bitter pit in fruit from the upper and peripheral parts of the canopy. Canopy size, local climatic conditions, and cultivar may have contributed to the conflicting results. Therefore, there is a need to assess the influence of canopy position on bitter pit development in intensive orchards in humid regions.

The first objective of our study was to identify some of the within-canopy factors associated with bitter pit development on 'Honeycrisp' apples grown in intensive orchards in the humid mid-Atlantic region. A second objective was to demonstrate the use of 
logistic regression in horticultural research in which the response variable is binomial. In our study, we used logistic regression to predict the probability of individual fruit to develop bitter pit.

\section{Materials and Method}

Aspers orchard 1. Nine 8-year-old 'Honeycrisp' trees on M.9 Nic29 rootstock with moderate crop loads were selected in a commercial orchard in Aspers, PA (lat. $39.9772^{\circ} \mathrm{N}$, long. $77.2251^{\circ} \mathrm{W}$ ). Rows were oriented north-south, and trees were spaced at $4.9 \times 1.5 \mathrm{~m}$, trained as vertical axis, and were $\approx 3.6 \mathrm{~m}$ tall. On 25 Aug. 2016, $4 \mathrm{~d}$ before the first commercial spot picking, one spur with one fruit and one spur with two fruit were removed from four canopy positions on each tree (high north side, low north side, high south side, and low south side). The intact spurs with bourse shoots and leaves were placed in plastic bags and transported on ice in a cooler to the laboratory. For each spur, the number of bourse shoots was recorded, along with the total length of bourse shoots and the number of leaves per spur. Each fruit was numbered with a permanent marker to identify the spur, canopy position, and tree. Each fruit was then weighed, and the percentage of fruit surface covered with red blush was estimated visually to the nearest $10 \%$. The fruit were then placed in cold storage at $3 \pm 2{ }^{\circ} \mathrm{C}$ and were removed in early January. After $7 \mathrm{~d}$ at $20^{\circ} \mathrm{C}$, the number of pits was recorded for each fruit.

Aspers orchard 2. Eight trees with moderately heavy crops were selected from a block of 8-year-old 'Honeycrisp' trees on M.9 NAKBT337 rootstock. Rows were oriented northeast-southwest, and trees were spaced at $4.3 \times 1.2 \mathrm{~m}$, trained as vertical axis, and were $\approx 3.6 \mathrm{~m}$ tall. On 25 Aug. 2016, one branch bearing three to five spurs with single fruit, from the north and south side of each tree at a height of $\approx 1.5 \mathrm{~m}$ aboveground, was removed from each tree. Each fruit on a branch was numbered sequentially from the terminal end, and the branches along with fruit attached were placed in plastic bags for transportation to the laboratory. Branches, spurs, and fruit were processed as described earlier, except the distance from the terminal bud of the branch to each fruit was also recorded.

Received for publication 23 June 2021. Accepted for publication 30 July 2021.

Published online 1 February 2022.

This work was supported by the U.S. Department of Agriculture, National Institute of Food and Agriculture and Hatch Appropriations under project no. 4625 and accession no. 1006805; and the Pennsylvania Department of Agriculture Research Program. We acknowledge the valuable contributions of Chris Baugher (grower cooperator).

R.P.M. is the corresponding author. E-mail: rpm12@psu.edu.

This is an open access article distributed under the CC BY-NC-ND license (https://creativecommons. org/licenses/by-nc-nd/4.0/).
Rock Springs 2016. Seven 9-year-old 'Honeycrisp' trees on M.26 rootstock growing at the Russell E. Larson Agricultural Research Center at Rock Springs, PA (lat. $40.70944^{\circ} \mathrm{N}$, long. $77.9533^{\circ} \mathrm{W}$ ) were selected. Rows were oriented northwest-southeast, and trees were trained as vertical axis, spaced at $2.75 \times 1.5$ $\mathrm{m}$ and were $\approx 3.6 \mathrm{~m}$ tall. Trees had light crop loads as a result of a spring frost. On 6 Sept. 2016 , one to three branches with fruit were removed from three canopy positions on each tree (low outside, high outside, or low inside) on the east and west sides of each tree. Branches consisted of 1-, 2-, 3-, and 4-yearold wood. The low positions were $\approx 0.7 \mathrm{~m}$ aboveground and the high position was $\approx 2.4$ $\mathrm{m}$ aboveground. The reason that varying numbers of branches were sampled on different trees was because some trees had more branches with adequate numbers of fruit than others. Branches with leaves and fruit were placed in plastic bags and transported to the laboratory for measurements. The number of fruit per spur was recorded for each spur. The total length of all shoots on each branch was recorded, as were the number of leaves and the maximum diameter of the 4-year-old branch section. Each fruit was numbered to identify the spur, canopy position, and tree. Fruit were weighed, and the percentage of surface of each fruit with red blush was estimated to the nearest $10 \%$. The fruit were then placed in cold storage at $3 \pm 2{ }^{\circ} \mathrm{C}$ and were removed in early Jan. 2017. After $7 \mathrm{~d}$ at $20^{\circ} \mathrm{C}$, the number of pits was recorded for each fruit.

Rock Springs 2019. Nine trees in the same planting as described for 2016 were selected in 2019. Trees had a heavy crop load because they were not chemically or hand-thinned to ensure there would be spurs with multiple fruit. The day before trees were harvested, one spur with one, two, or three fruit with leaves was removed from the inside and outside of each tree from the lower part of the canopy ( $\approx 0.7 \mathrm{~m}$ aboveground) on the south and north sides of each tree. In addition, spurs were removed from the outside of the upper part of the canopy $\approx 2.4 \mathrm{~m}$ aboveground on the south side of the canopy. Spurs with fruit were placed in bags and brought to the laboratory for measurement. Fruit were removed from the spur and labeled to designate the spur, canopy position, and tree. The number of leaves per spur was recorded. The largest two leaves per spur were measured to estimate leaf area.

Leaves were then placed in coin envelops, dried at $70^{\circ} \mathrm{C}$, and weighed to estimate specific leaf weight (SLW), measured in milligrams per square centimeter. SLW was recorded because it is a biological integrator of light interception (Marini and Barden, 1981). Each fruit was weighed and the percentage of the fruit surface with red blush was estimated visually to the nearest $10 \%$. Fruit were placed in cold storage at $3 \pm 2{ }^{\circ} \mathrm{C}$ and were removed in early Jan. 2020. After 7 d at $20^{\circ} \mathrm{C}$, the number of pits was recorded for each fruit.

Statistical analyses. For each experiment, there was a factorial treatment structure consisting of two or more tree sides, two or more canopy positions (inside vs. outside), or number of fruit per spur in a randomized complete block design, where trees were blocks. Analysis of variance (ANOVA) was performed with SAS's PROC GLIMMIX (SAS version 9.4; SAS Institute, Inc., Cary NC) to test the hypotheses that bitter pit severity (number of pits/fruit) and incidence (proportion of fruit with bitter pit) were equal for all levels of these factors and block was a random effect. When interactions involving only qualitative variables were significant, LSmeans for each level of a variable were compared within each level of the other variables (tree side, canopy position, and number of fruit per spur) with the Slicediff option in the LSmeans statement.

To determine whether continuous variables (distance from fruit to terminal bud, FW, SLW, number of leaves per spur, and percentage of fruit red blush) were associated with bitter pit severity, analysis of covariance was performed with PROC GLIMMIX, in which canopy position and number of fruit per spur were included as indicator (qualitative) variables, and continuous variables were included as covariates or regressor variables. Interaction terms for indicator variables and continuous variables were also included in the models. The 2019 experiment had an augmented factorial structure (Marini, 2003) because there were two canopy positions $x$ two tree sides in the lower canopy plus the upper outside canopy position. In those cases, data were analyzed with one-way ANOVA and preplanned contrasts to test main effects and interactions. Residuals for proportion data from three experiments were not distributed normally before or after the proportion data were transformed to the arcsine of the square root of the proportion or the square root of the proportion $(P<0.005)$. Therefore, nontransformed proportion data were analyzed with the knowledge that the F tests may not be valid.

The presence or absence of bitter pit for each fruit was also recorded as a binary response (yes, no). Binary data are often analyzed with binary logistic regression because residuals are not distributed normally. Logistic regression is an extension of simple linear regression. However, logistic models cannot account properly for random effects such as blocks. Therefore, these data were analyzed with PROC GLIMMIX using individual-event data as described by Kiernan (2018). To avoid biased variance estimates for the variance components, the maximum likelihood method (Method=Quad) was requested. Options in the model statement included the dist=binary and link=logit to request the binomial distribution. The predicted probabilities for each fruit were output to a new dataset using the inverse link function in the output statement [predicted(blup ilink)=predprob]. The predicted probabilities were then used in PROC LOGISTIC to generate graphs of the receiver-operating characteristic (ROC) curve and the area under the ROC curve (AUC) (Kiernan, 2018). PROC LOGISTIC was also used to perform tests to compare the ROC curves from competing models (models with different regressor variables). 
The ROC curve was developed for operators of military radar receivers and is commonly used in psychophysics, medicine, and radiology to predict a binary outcome (Park et al., 2004). In our study there were four potential outcomes when predicting whether an apple would develop bitter pit: 1) true positive, when a model predicts correctly that an apple will develop bitter pit; 2) true negative, when a model predicts correctly that an apple will not develop bitter pit; 3) false negative, when a model predicts incorrectly that an apple will not develop bitter pit; and 4) false positive, when a model predicts incorrectly that an apple will develop bitter pit. A ROC curve is a plot of a test's sensitivity ( $y$-axis), which is the true-positive rate, against 1-specificity ( $x$-axis), which is the false-positive rate (Gönen, 2006). To produce ROC curves, the predicted probability is transformed into a dichotomy using thresholds and reporting results for each threshold, where each point on the curve corresponds to a specific threshold. The points can be connected to produce an empirical ROC curve. ROC curves may be enhanced by including a $45^{\circ}$ line. This reference line represents the ROC curve for a random guess $(50 \%$ chance of classifying correctly that an apple will develop bitter pit) and is sometimes called the "chance diagonal." A model that predicts bitter pit accurately produces a curve that ascends very quickly and vertically from the origin toward the upper left corner of the plotting area, then curves quickly to the right, with a long flat line across the top of the chart (Fig. 1). AUC is the most popular method of summarizing the accuracy of a model with a single number (Gönen, 2006). A model with predictions that are $100 \%$ wrong has an AUC of 0.0 ; a model with predictions that are $100 \%$ correct has an AUC of 1.0. A model with an AUC of 0.5 is correct half the time and is no better than flipping a coin. In general, an AUC of 0.5 indicates that the model has little discriminatory ability and cannot classify accurately fruit that will develop bitter pit. An AUC of 0.7 to 0.8 is considered acceptable, 0.8 to 0.9 is considered excellent, and more than 0.9 is considered outstanding (Hosmer and Lemeshow, 2000). AUC curves of a variable are often compared with chance (Shin and Coulter 2009); when the estimated AUC is statistically greater than 0.5 , there is evidence the model is useful for classifying correctly fruit with bitter pit and fruit without bitter pit.

\section{Results}

Aspers orchard 1. The side of the tree from which fruit were harvested did not affect significantly the number or length of bourse shoots per spur, number of leaves per spur, or FW (data not shown). The percentage of the fruit surface colored red was slightly greater for the south side than the north side of the tree $(37.8 \%$ vs. $28.3 \%, P=0.084)$, and number of pits per fruit was not affected significantly by tree side (north, $\mathrm{n}=13.4$; south, $\mathrm{n}=$ $10.1 ; P=0.425)$. To predict bitter pit severity (number of pits per fruit), a model was fit

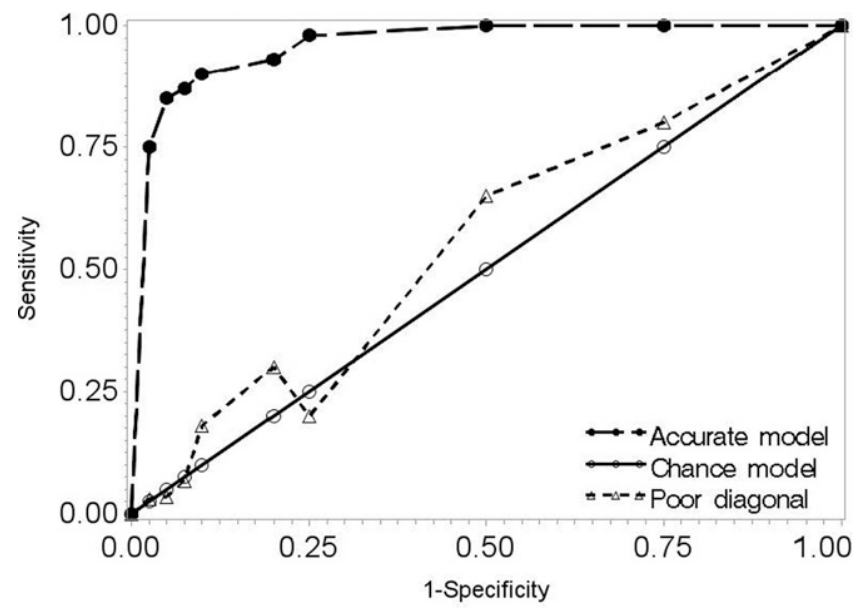

Fig. 1. Example of two operating characteristic curves. The accurate model predicts accurately the probability that an apple will develop bitter pit. The chance diagonal represents a model with a $50 \%$ chance of classifying correctly an apple as developing bitter pit. The accuracy of the poor model is slightly better than chance.

with tree side, canopy position, distance from the terminal, number of bourse shoots, bourse shoot length, fruit red color, and FW as independent variables. After manual backward elimination of nonsignificant variables, only distance from the terminal and FW were significant $\left(R^{2}=0.52\right)$. Bitter pit severity increased linearly with increasing FW and distance from the terminal (Fig. 2).

When the presence of bitter pit was treated as a binary variable, the logistic model with tree side, $\mathrm{FW}$, and the interaction of tree side $\times \mathrm{FW}$ was significant $(P=0.04)$. The estimated probability of a fruit developing bitter pit increased with increasing FW, and was greater for the north side than the south side of the tree (Fig. 3). The probability of a small fruit $(200 \mathrm{~g})$ developing bitter pit was

0.5 and 0.8 for fruit harvested from the south and north sides of the tree, respectively. The probability of large fruit $(>300 \mathrm{~g})$ developing bitter pit was nearly 1.0 regardless of tree side. The AUCs were 0.617, 0.628, and 0.749 , respectively, for models with only the distance from the terminal, tree side, or FW (Fig. 4). The AUC for the multiple logistic regression GLIMMIX model containing all three variables was 0.857 .

Contrasts comparing each model to "chance," indicated that only the logistic model with FW and the GLIMMIX model with all three variables were significantly better than chance $(P<0.001)$. GLIMMIX is preferred because it contains more than one significant variable and accounts for the random effect of tree.

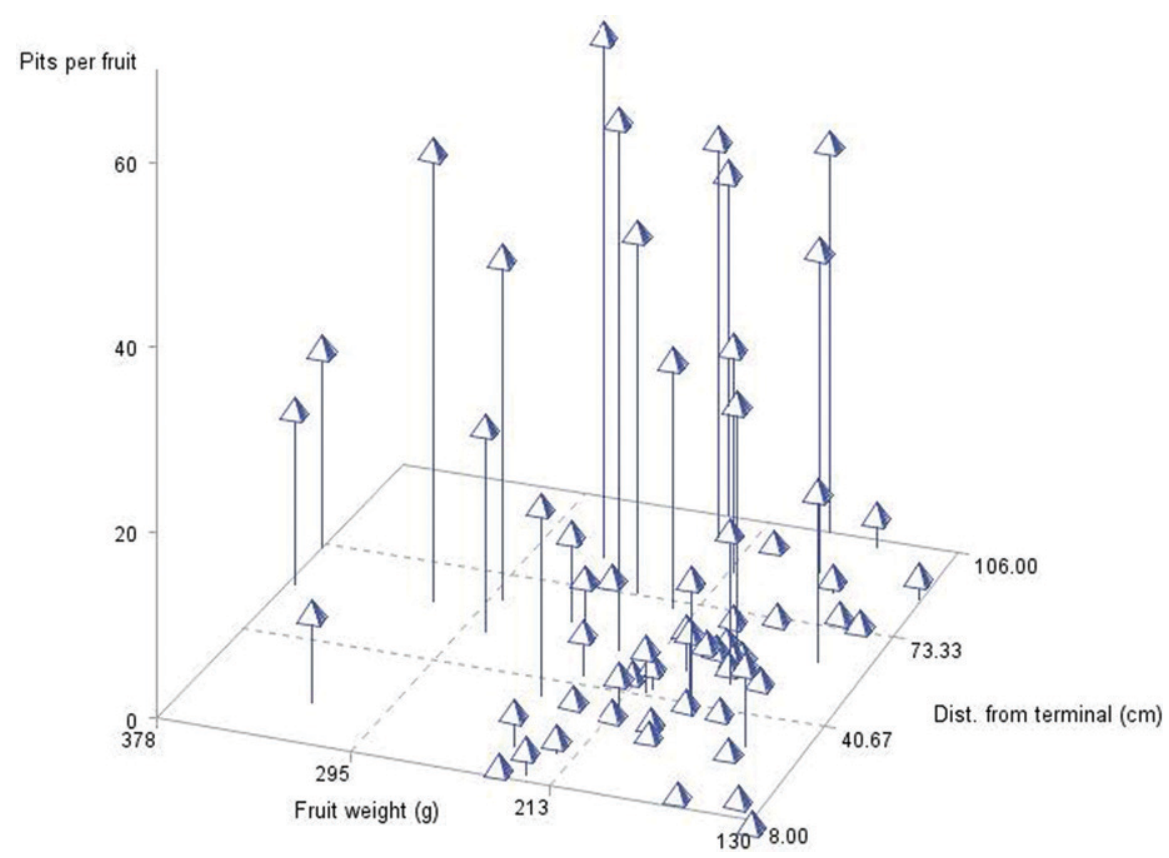

Fig. 2. Three-dimensional scatterplot showing the relationship between the number of pits per fruit after storage as influenced by fruit weight (FW) and distance (Dist.) from the shoot terminal to the fruiting spur. The multiple regression model is as follows: No. of pits per fruit $=-36-83+$ $0.164(\mathrm{FW})+0.247$ (Dist.); $R^{2}=0.52, P=0.0001, \mathrm{~N}=60$. 


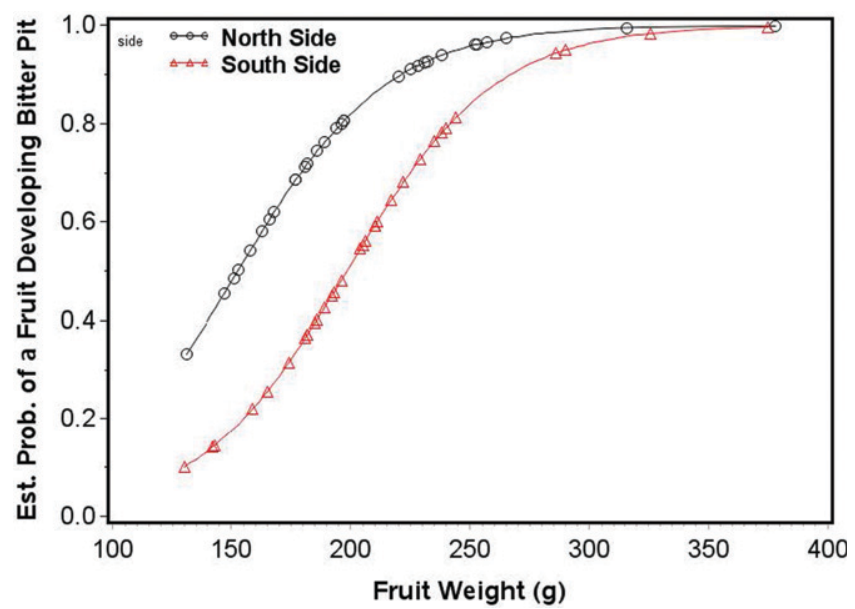

Fig. 3. The relationship between predicted probability (Prob.) of a 'Honeycrisp' fruit developing bitter pit and fruit weight as influenced tree side for Aspers orchard 1.

Aspers orchard 2. Because branches had varying numbers of fruit, the number of observations per tree side was highly variable, with a total of $8,33,37$, and 12 fruit from the east, north, south, and west sides of the tree, respectively. Average FW was 165, 208, 234, and $168 \mathrm{~g}$ for the east, north, south, and west sides of the tree. The mean number of pits per fruit was $11.1,15.5,16.8$, and 18.4 for fruit from the east, north, south, and west sides of the tree. Because of the lack of observations for the east and west sides, the LSmeans from the four-way ANOVA could not be estimated, so tree side was deleted from the model. The influence of canopy position for most spur characteristics depended on crop load. The canopy position $\times$ crop load interaction was significant for number of bourse shoots per spur, leaves per spur, FW, percentage surface red blush, and number of pits per fruit (Table 1). For trees with high crop loads, spurs from the upper canopy had more bourse shoots and leaves per spur than spurs from the lower canopy. For trees with low crop loads, FW was greatest for spurs from the lower canopy of trees. The opposite was true for trees with high crop loads, where FW as lowest for spurs from the lower canopy. In addition, for trees with low crop loads, red color was greater for fruit from the upper canopy than fruit from the lower canopy. For trees with low crop loads, number of pits per fruit was greatest for fruit from the upper canopy. In contrast, for trees with high crop loads, number of pits per fruit was lowest for fruit from the upper canopy. The proportion of fruit developing bitter pit was affected only by canopy position, with $49 \%$ and $87 \%$ of the fruit from the upper and lower canopy, respectively. Shoot length and number of leaves per spur were correlated $\left(R^{2}=0.84\right.$, $P=0.001, \mathrm{n}=82$ ). To avoid collinearity, only the number of leaves per spur and fruit per spur were included in models to predict pits per fruit, and there was an interaction between the two variables $(P=0.001)$. For fruit on spurs with a single fruit, the number of pits per fruit related positively to number of leaves per spur. In contrast, the relationship was higher order interactions involving crop load and number of leaves per spur. When results from PROC GLIMMIX were compared with PROC LOGISTIC, $P$ values and AUCs were different (AUCs were 0.864 vs. 0.797 for GLIMMIX vs. LOGISTIC, respectively) because the logistic model does not account for the random effect of tree. Based on the resulting ROC and AUC curves, the two singlevariable models with the highest AUC were crop load (AUC $=0.72$ ) and leaves per limb (AUC $=0.582$, Fig. 6). Only crop load was significantly better than chance $(P<0.05)$. Based on the AUC, leaves per limb was poor at classifying correctly a fruit that will develop bitter pit, but the model with crop load was acceptable. However, the model containing both leaves per limb and crop load was excellent $(\mathrm{AUC}=0.86)$. As leaves per limb increased, the probability of a fruit developing bitter pit declined, and fruit from trees with low crops had a greater probability of developing bitter pit than fruit from trees with high crop loads (Fig. 7).

Rock springs 2016. Number and length of bourse shoots per spur and the number of leaves per spur were not affected significantly by tree side, canopy position, or number of fruit per spur (data not shown). The effect of tree side on FW depended on the number of fruit per spur because the interaction of tree side $\times$ number of fruit per spur was significant and leaves per spur) had several significant

negative when there were two fruit per spur, poor $\left(R^{2}<0.24\right.$, Fig 5). One models were the interaction, may be that spurs with one fruit tended to have more leaves than spurs with two fruit.

The binary analysis performed with PROC GLIMMIX with four indicator variables (crop load, tree side, canopy height, and ROC Curves for Comparisons

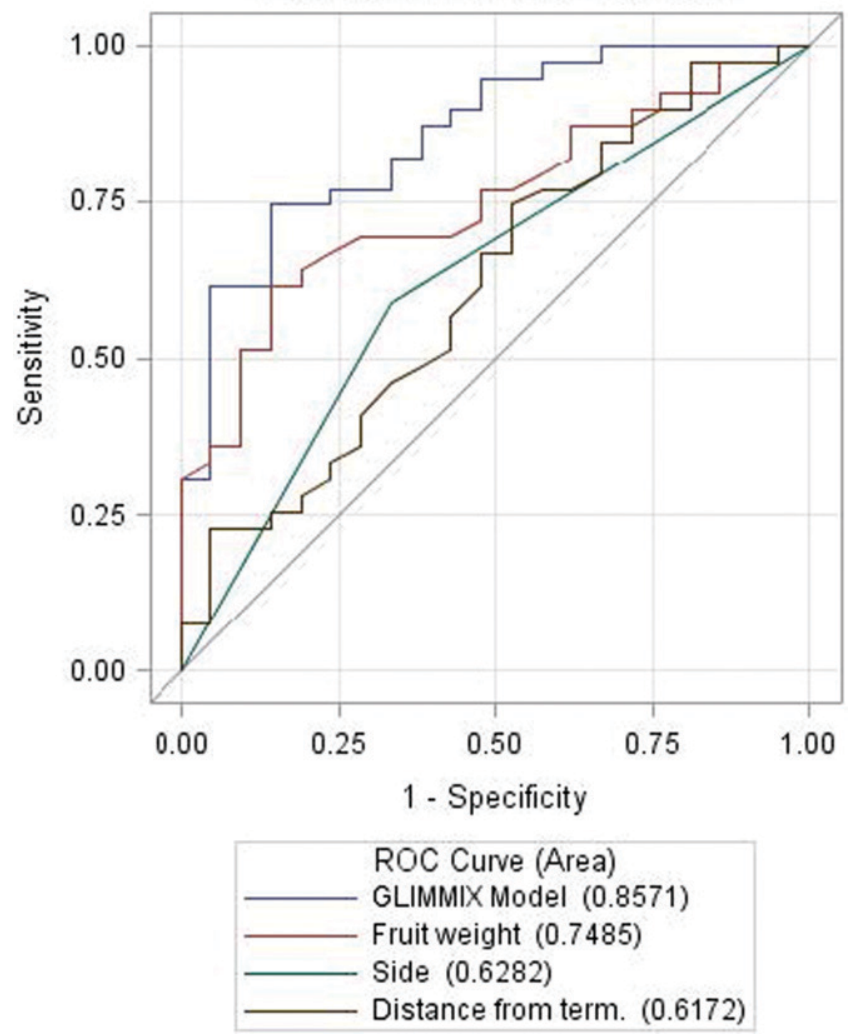

Fig. 4. Empirical receiver-operating characteristic (ROC) curves showing the diagnostic abilities of four models to predict the probability of a 'Honeycrisp' fruit harvested from Aspers orchard 2 to develop bitter pit. Simple logistic regression models contained distance from the shoot terminal (term.), but to the spur (brown line), the side of the tree (green line), and fruit weight (red line). The multiple logistic regression GLIMMIX model contains all three variables (blue line). Values in parentheses are areas under the curve and give the rate a of successful classification by model. 
Table 1. The influence of crop load and canopy height on the number and length of bourse shoots per spur, number of leaves per spur, average fruit weight $(\mathrm{FW})$, red fruit color, and pits per fruit after cold storage for 'Honeycrisp' apples harvested from Aspers orchard 2 in 2016.

\begin{tabular}{|c|c|c|c|c|c|c|c|}
\hline Crop load & $\begin{array}{c}\text { Canopy } \\
\text { ht }\end{array}$ & $\begin{array}{c}\text { Bourse } \\
\text { shoots/spur }\end{array}$ & $\begin{array}{l}\text { Shoot length/ } \\
\text { spur }(\mathrm{cm})\end{array}$ & $\begin{array}{l}\text { Leaves/ } \\
\text { spur }\end{array}$ & FW (g) & $\begin{array}{c}\text { Red } \\
\text { color }(\%)\end{array}$ & $\begin{array}{l}\text { Pits/ } \\
\text { fruit }\end{array}$ \\
\hline High & High & $1.9 \mathrm{a}$ & 21.1 & $15.7 \mathrm{a}^{\mathrm{z}}$ & $217 a$ & $17.3 \mathrm{a}$ & $4.7 \mathrm{a}$ \\
\hline High & Low & $1.2 \mathrm{~b}$ & 16.6 & $9.8 \mathrm{~b}$ & $192 \mathrm{a}$ & $20.8 \mathrm{a}$ & $8.9 \mathrm{a}$ \\
\hline Low & High & $1.3 \mathrm{~A}^{\mathrm{y}}$ & 21.4 & $12.6 \mathrm{~A}$ & $242 \mathrm{~A}$ & $48.9 \mathrm{~A}$ & $31.6 \mathrm{~A}$ \\
\hline Low & Low & $1.7 \mathrm{~A}$ & 14.8 & $14.5 \mathrm{~A}$ & $263 \mathrm{~A}$ & $14.8 \mathrm{~B}$ & $13.3 \mathrm{~B}$ \\
\hline \multicolumn{8}{|l|}{$P$ value ${ }^{\mathrm{x}}$} \\
\hline Crop load & & 0.221 & 0.217 & 0.535 & 0.049 & 0.466 & 0.528 \\
\hline $\mathrm{Ht}$ & & 0.006 & 0.489 & 0.109 & 0.050 & 0.309 & 0.934 \\
\hline Crop $\times h$ & & 0.002 & 0.667 & 0.039 & 0.049 & 0.002 & 0.050 \\
\hline
\end{tabular}

${ }^{\mathrm{z}}$ Values within high crop load followed by similar lowercase letters do not differ at the $5 \%$ level of significance, by slice diff in GLIMMIX.

${ }^{y}$ Values within low crop load followed by similar uppercase letters do not differ at the $5 \%$ level of significance, by slice diff in GLIMMIX.

${ }^{\mathrm{x}}$ From analysis of variance.

at the 0.053 level. For spurs on the east side of the tree with one or two fruit per spur, FW was $238 \mathrm{~g}$ and $213 \mathrm{~g}$, respectively. For the west side, FW was $254 \mathrm{~g}$ and $201 \mathrm{~g}$, respectively, for spurs with one or two fruit. FW was also significantly less for fruit from the inside low-canopy position $(210 \mathrm{~g})$ than for fruit from the outside high- and outside low-canopy positions (242 and $249 \mathrm{~g}$, respectively, $P=$ $0.016)$. Fruit from the east side of the tree were redder than fruit from the west side (38\% vs. $31 \%, P=0.031$ ). Fruit from the upper outside and lower outside were redder ( $48 \%$ and $41 \%$, respectively, $P=0.001)$ than fruit from the lower inside $(14 \%)$ of the canopy. Fruit from spurs with one fruit were redder than fruit from spurs with two fruit $(38 \%$ vs. $31 \%, P=0.033)$. The number of pits per fruit was affected by the interaction of tree side and number of fruit per spur $(P=0.006)$. Fruit on the east side of the tree averaged 9.5 and 15.9 pits for spurs with one or two fruits respectively. In contrast, fruit on the west side of the tree averaged 11.5 and 5.1 pits for spurs with one or two fruit, respectively.

Results from fitting a covariance model for pits per fruit indicated that FW and the FW $\times$ canopy position interaction were significant. For the upper canopy position, pits per fruit related positively to FW (data not shown). For the lower canopy position, pits

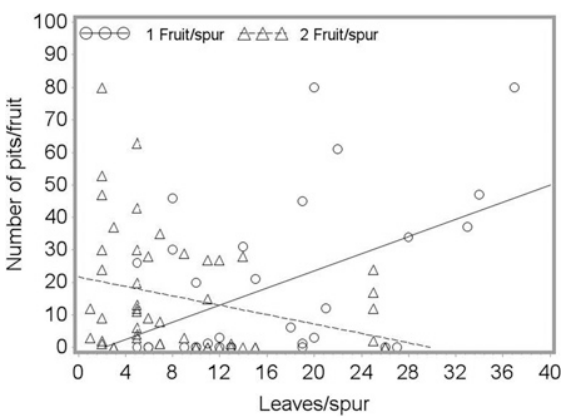

Fig. 5. The relationship between pits per fruit and number of leaves per spur for 'Honeycrisp' fruit as influenced by the number of fruit per spur harvested from Aspers orchard 2. The regression equations are the following: for 1 fruit/spur, Pits $=2.87+1.32$ (leaves), $R^{2}=0.23, P=$ $0.007, \mathrm{n}=31$; for 2 fruit $/$ spur $=$ Pits $=21.63-$ 0.725 (leaves), $R^{2}=0.084, P=0.043, \mathrm{n}=51$. per fruit was not related to FW. Pits per fruit was not related to tree side, fruit per spur, fruit red color, or leaves per spur.

Analysis of bitter bit incidence with the same indicator variables showed that $\mathrm{FW}$, canopy position, $\mathrm{FW} \times$ canopy position, and tree side $\times$ number of fruit per spur were significant. In general, fruit from spurs with one fruit had a greater incidence of bitter pit than fruit from spurs with two fruit, but it depended on tree side $(P=0.019)$. On the west side of the tree, spurs with one fruit had the greatest incidence of bitter pit $(81 \%)$ and spurs with two fruit had the lowest incidence $(34 \%)$. Fruit from the east side were intermediate. Fruit from the upper canopy had a lower incidence of bitter pit than fruit from the lower canopy or the interior canopy $(P=$ 0.033 ). For the ROC curve, the AUC was 0.712 for $\mathrm{FW}$ and 0.605 for canopy position, and both were significant at the 5\% level (Fig. 8). The AUC was 0.76 for the LOGISTIC model and 0.84 for the GLIMMIX model containing both FW and canopy position. This model had an excellent ability to classify correctly which fruit will develop bitter pit. The probability that a fruit will develop bitter pit increased with increasing FW (Fig. 9). In addition, fruit sampled from the lower interior canopy position had a greater probability of developing bitter pit than fruit from the upper outside canopy position. The lower outside canopy position was intermediate (Fig. 9). For small fruit $(200 \mathrm{~g})$, the probability of a fruit developing bitter pit was $0.4,0.5$, and 0.75 for fruit from the upper outside, lower outside, and lower inside canopy positions, respectively. For large fruit $(300 \mathrm{~g})$, the probability of a fruit developing bitter pit was $0.85,0.9$, and 0.98 , for fruit from the upper outside, lower outside, and lower inside canopy positions, respectively.

Rock Springs 2019. Leaves from spurs on the lower outside of the canopy had a greater SLW than leaves on the lower inside of the tree $\left(6.7\right.$ vs. $\left.5.6 \mathrm{mg} \cdot \mathrm{cm}^{-2}, P=0.001\right)$, and the SLW was greater for spurs from the upper outside canopy position than the lower outside canopy position $\left(7.4\right.$ vs. $6.7 \mathrm{mg} \cdot \mathrm{cm}^{-2}, P=$ $0.001)$. Fruit from the upper outside canopy were redder than fruit from the lower outside

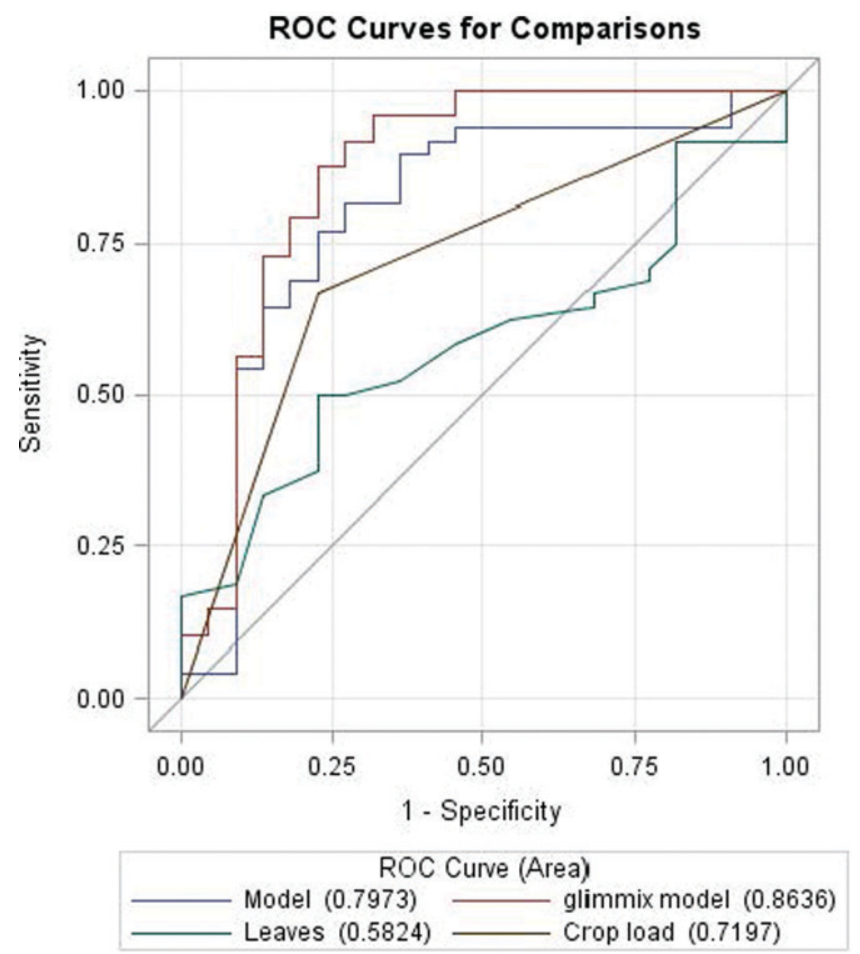

Fig. 6. Empirical receiver-operating characteristic (ROC) curves showing the diagnostic abilities of four models to predict the probability of a 'Honeycrisp' fruit harvested from Aspers orchard 2 to develop bitter pit. Simple logistic regression models contained crop load (brown line) or number of leaves per limb (green line). Multiple logistic regression models containing both variables were developed with PROC LOGISTIC (blue line) and PROC GLIMMIX (red line). The GLIMMIX model is better because it accounts for the random effect of tree properly. Values in parentheses are areas under the curve and give the rate a of successful classification by model. 


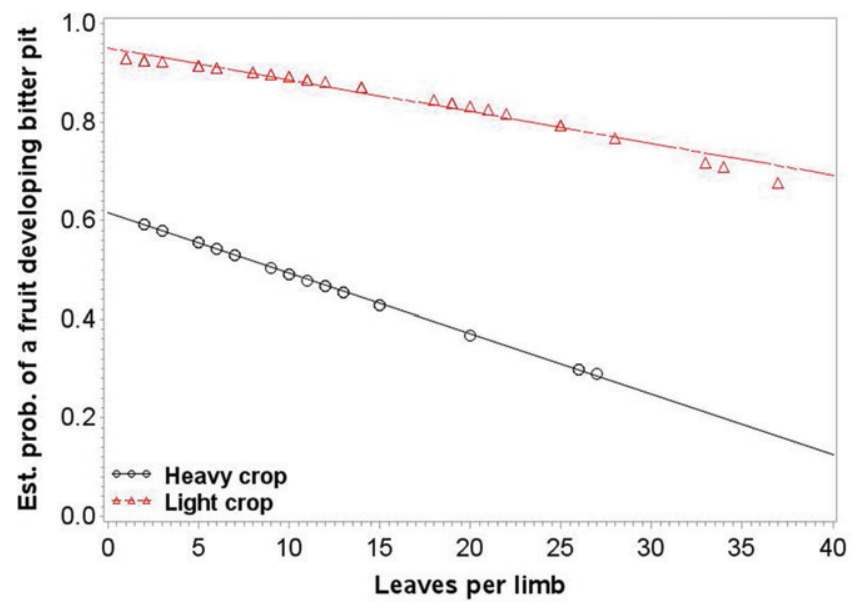

Fig. 7. The influence of crop load on the relationship between the probability (prob.) of 'Honeycrisp' fruit developing bitter pit and number of leaves per limb for Aspers orchard 2.

canopy $(73 \%$ vs. $65 \%, P=0.001)$, and fruit from the lower outside canopy were redder than fruit from the lower insider canopy $(65 \%$ vs. $52 \%, P=0.003)$. FW was greater for fruit from the lower outside of the canopy than from the lower inside canopy (204 vs. $190 \mathrm{~g}, P=0.003)$. The ROC curve from the LOGISTIC model showed that number of fruit per spur and FW influenced significantly the probability that a fruit will develop bitter pit $(P=0.05)$. The AUC for the GLIMMIX model containing both variables was 0.72 , indicating that the model is acceptable for categorizing which fruit will develop bitter pit

(Fig. 10). Thus, the probability of a fruit developing bitter pit increased linearly with increasing FW. In contrast, the probability of a fruit developing bitter pit declined with increasing number of fruit per spur (Fig. 11). For example, the probability that medium-size fruit $(250 \mathrm{~g})$ would develop bitter pit was 0.5, 0.39, and 0.3 for fruit from spurs with one, two, and three fruit, respectively.

\section{Discussion}

General results. Various characteristics of fruit and spurs at different canopy positions

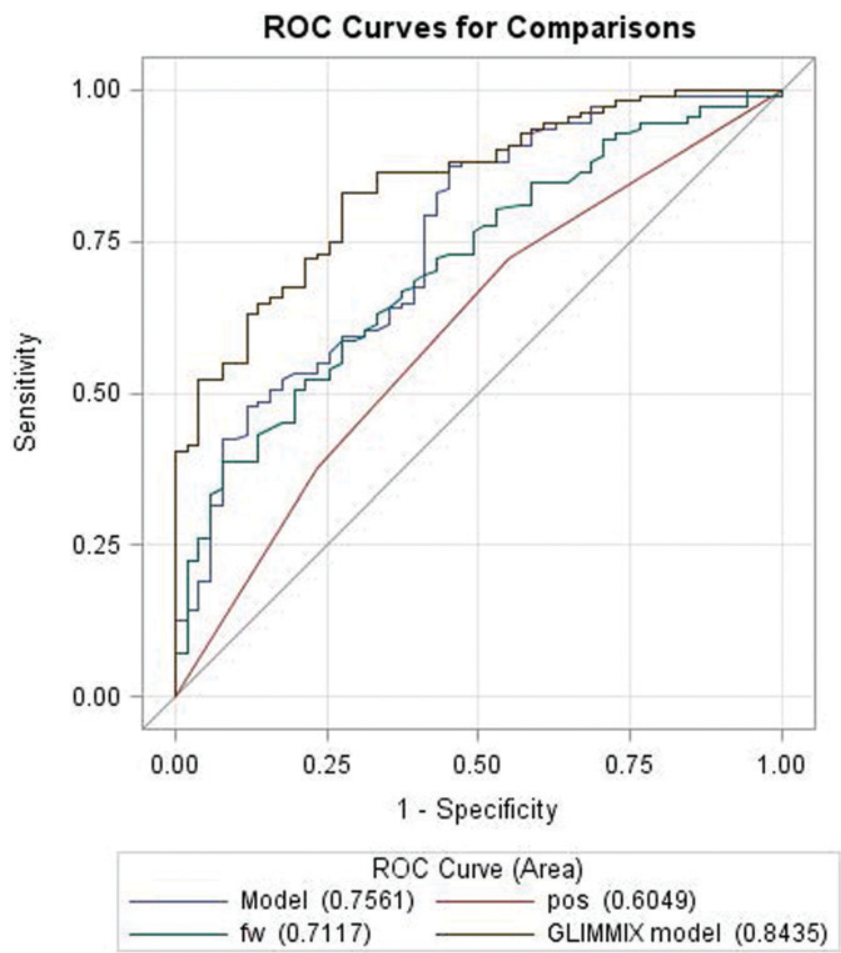

Fig. 8. Empirical receiver-operating characteristic (ROC) curves showing the diagnostic abilities of four models to predict the probability of 'Honeycrisp' fruit harvested from Rock Springs in 2016 to develop bitter pit. Simple logistic regression models contained canopy position (pos) (red line) or fruit weight (fw) (green line). Multiple logistic regression models containing both variables were developed with P ROC LOGISTIC (blue line) and PROC GLIMMIX (brown line). The GLIMMIX model is better because it accounts for the random effect of tree properly. Values in parentheses are areas under the curve and give the rate a of successful classification by the model. were quantified in our study to identify fruit that are most likely to develop bitter pit. Spur and fruit characteristics were not affected consistently by canopy position. However, across the four experiments, bitter pit was often associated with certain characteristics of fruit and spurs, and it sometimes depended on canopy position. Incidence of bitter pit (proportion of fruit with bitter pit) was influenced more consistently by canopy position, spur characteristics, and FW than was bitter pit severity (number of pits per fruit). Large fruit had consistently greater probabilities of developing bitter bit than small fruit. Fruit from spurs with one fruit and spurs with many leaves had a greater probability of developing bitter pit than fruit from spurs with multiple fruit and spurs with few leaves. To our knowledge, this is the first study in which bitter pit was evaluated for varying numbers of fruit per spur, and the effect of fruit per spur often depended on other factors, especially FW.

Appropriateness of logistic regression. Serra et al. (2016) used logistic regression to compare distributions of bitter pit incidence under netting, but our study is the first to use logistic regression to estimate the probability that individual fruit will develop bitter pit. Logistic regression has two advantages over the ANOVA and regression approaches typically used to analyze the proportion of apples developing bitter pit. First, logistic regression provides information about individual fruit rather than an average estimated from a sample of multiple fruit of varying sizes and from spurs with varying numbers of fruit. Therefore, logistic regression uses information related to fruit-to-fruit variation. Second, residuals from proportion data are usually not distributed normally, and commonly used transformations often do not correct the problem. Proportion data are usually transformed in an attempt to satisfy assumptions for ANOVA or regression analysis. In most cases, authors do not indicate whether the assumptions were tested before or after data transformation. However, proportion data subjected to the arcsine or square root transformations often do not satisfy the assumptions for parametric tests adequately (Llewelyn, 1968; Marini et al., 1993). Ahrens et al. (1990) also reported that the arcsine transformation can have adverse effects on some datasets. In our study, residuals for proportion data were distributed normally for only one of the four datasets, as indicated by residual plots and the four test statistics generated by SAS's PROC UNIVARIATE. Logistic regression was developed for data with binomial distributions. Warton and Hui (2011) stated that "transformation is recommended in statistical texts for biologists and ecologists, but not in many applied regression texts aimed at practicing statisticians because the arcsine transformation has been superseded by more modern methods of analysis such as logistic regression" (p. 3).

In previous research, the proportion of fruit developing bitter pit was usually estimated from bulk samples of fruit harvested from individual trees (Baugher et al., 2017), a group of trees (Al Shoffe et al., 2019), 


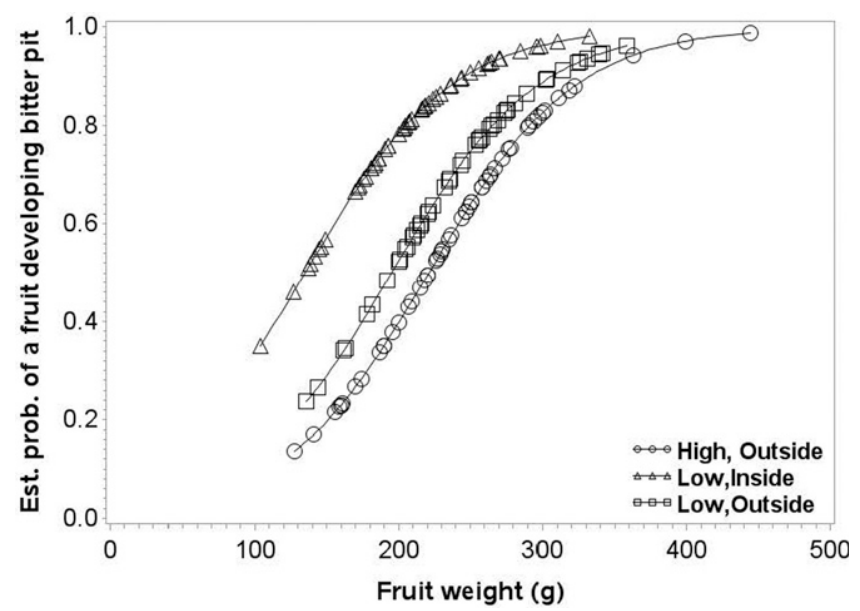

Fig. 9. The probability (prob.) of 'Honeycrisp' fruit developing bitter pit as affected by fruit weight for fruit harvested from three canopy positions at Rock Springs in 2016.

canopy positions within trees (Jackson and Sharples, 1971; Kalcsits et al., 2019), or fruit size categories (Ferguson and Watkins, 1992; Ferguson and Triggs, 1990). After storage, the proportion of fruit developing bitter pit correlated with the average $\mathrm{FW}$ for the same bulk sample. In other cases, samples of fruit were divided, and some fruit were used for mineral analysis, and the average concentration of calcium or ratios of elements correlated with the proportion of the remaining sample of fruit that developed bitter pit (Baugher et al., 2017; Ferguson and Watkins, 1992; Perring and Jackson, 1975; Serban and Kalcsits, 2018). Pooling fruit samples does

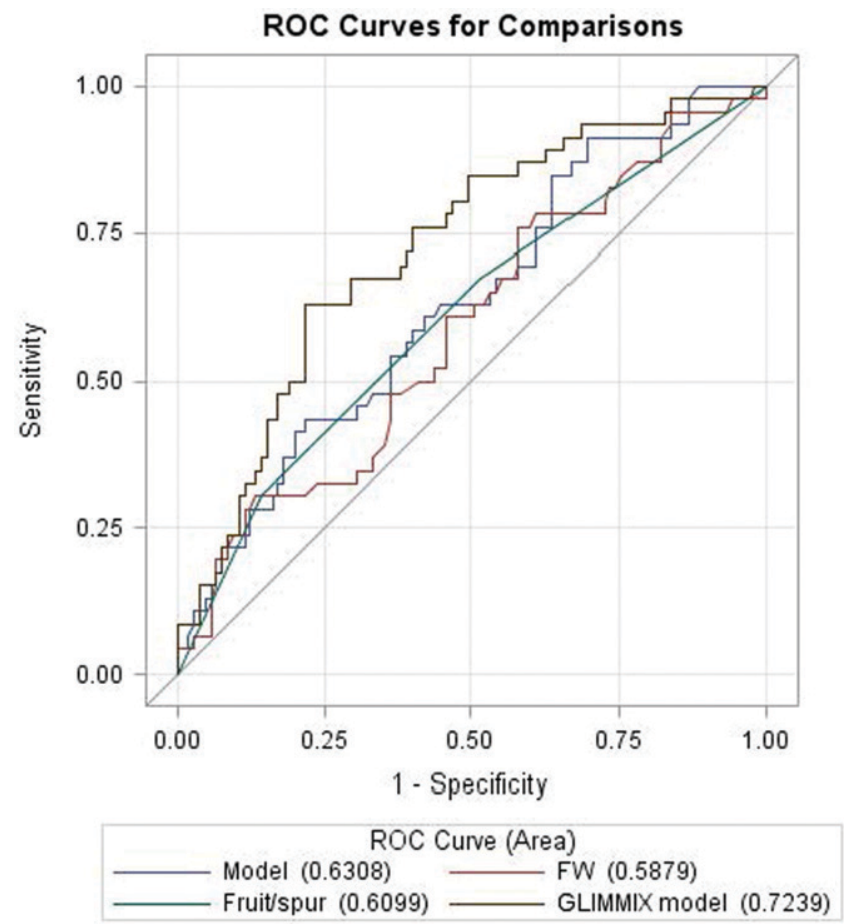

Fig. 10. Empirical receiver-operating characteristic (ROC) curves showing the diagnostic abilities of four models to predict the probability of 'Honeycrisp' fruit harvested from Rock Springs in 2016 to develop bitter pit. Simple logistic regression models contained fruits per spur (light-blue line) or fruit weight (FW) (red line). Multiple logistic regression models containing both variables were developed with P ROC LOGISTIC (dark-blue line) and PROC GLIMMIX (brown line). The GLIMMIX model is better because it accounts for the random effect of tree properly. Values in parentheses are areas under the curve and give the rate of successful classification by the model. when individual apples were analyzed, the calcium concentration in individual fruit was often unrelated to FW. Perring and Jackson (1975) suggested that canopy positional effects may override the inverse relationship between calcium concentration and FW of individual fruit because the relationship between calcium concentration and FW differed for fruit sampled from the east and west sides of the tree. A great deal of information is lost by pooling samples of fruit containing fruit of varying sizes, and fruit from spurs with varying numbers of fruit and leaves, which cannot be accounted for in a parametric statistical model.

Our study is the first we are aware of in which bitter pit development could be estimated for individual fruit. Such analyses were not possible before the development of software for generalized linear mixed models, such as PROC GLIMMIX, which extends the capabilities of mixed models to non-Gaussian distributions (Schabenberger, 2005). Like linear regression, logistic regression cannot be used for experiments in which the experimental material is sampled destructively for fruit mineral analysis before fruit develop bitter pit. However, logistic regression is particularly appropriate when fruit are analyzed nondestructively for elements as reported by Kalcsits et al. (2019).

Bitter pit severity. Bitter pit severity (pits per fruit) is rarely reported because fruit with a single pit are unsaleable; however, it was recorded in our study as a continuous variable to determine whether severity was related to various fruit, spur, and canopy characteristics. Bitter pit severity was affected by canopy position in three of the four experiments, and it was related to FW in all four experiments. However, the relationship between bitter pit severity and FW usually depended on other factors, such as canopy position and/or number of fruit per spur. Our bitter pit severity results support the mineral analysis results of Volz et al. (1994), in which FW and fruit calcium concentration varied with spur age. However, their results differed with cultivar. For 'Braeburn', 3-year old spurs had lower FW and greater fruit calcium concentrations than fruit on 2-year-old spurs. For 'Granny Smith', 3-year-old spurs had small fruit, but also had lower calcium concentrations than 2year-old spurs. Kalcsits et al. (2019) reported a quadratic relationship between bitter pit incidence and distance from the tree periphery. Fruit sampled closest and farthest from the trunk had the greatest incidence of bitter pit.

Bitter pit severity was greatest for fruit on spurs with one fruit and few leaves. Although we did not record spur age, the relationship between fruit calcium and leaves per spur may vary with spur age. Volz et al. (1994) removed leaves to create a range of leaves per spur. They found that the calcium concentration of individual fruit increased with increasing total leaf area per spur for fruit on 2-year spurs and 1-year terminals, but not for fruit on 1 -year lateral spurs. They did not report the relationship between leaves per spur and FW or calcium concentration, which may also influence bitter pit. In a similar experiment, 


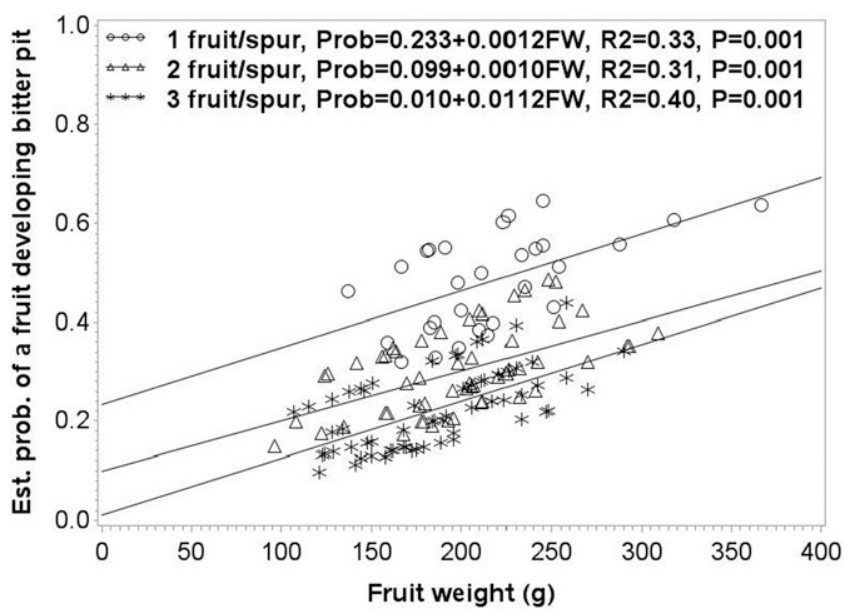

Fig. 11. Scatterplot with predicted lines showing the relationship between the probability of 'Honeycrisp' fruit developing bitter pit, and fruit weight (FW) as influenced by the of number of fruits per spur on for Rock Springs 2019.

Jones and Samuelson (1983) altered spur transpiration by removing some or all of the leaves or by enclosing leaves in polyethylene bags. Their treatments reduced the calcium concentration in the fruit. Because spur age, distance from the trunk, and shade are usually confounded, it is difficult to study the individual effects on bitter pit. Our results indicate that using bitter pit incidence is preferable to bitter pit severity as a response variable while studying bitter pit, because the mean number of pits per fruit is sensitive to a few fruit with many pits.

Crop load and bitter pit. High tree-to-tree crop load variation in Aspers orchard 2 allowed us to use crop load as an indicator variable. Fruit from trees with light crop loads had the greatest probability of developing bitter pit. This supports previous reports in which incidence of bitter pit related negatively to crop load (Ferguson and Watkins, 1989; Robinson and Lopez, 2012). Because FW is usually related negatively to crop load, separating the individual effects of the two variables on bitter pit is not possible when data are reported as a proportion of the fruit with bitter pit unless fruit are grouped into different fruit size categories. Recording bitter pit as a binary variable in our study, we found that the probability of a fruit developing bitter pit increased with increasing FW for trees with both low and high crop loads (Fig. 8). Therefore, small fruit on a tree will likely develop less bitter pit regardless of crop load. Perring and Jackson (1975) reported greater FW on light-cropping trees, and large fruit tended to have low calcium concentrations. Ferguson and Watkins (1992) also found that fruit from light-cropping trees had lower concentrations of calcium, along with greater concentrations of potassium, and a greater incidence of bitter pit regardless of FW.

Canopy position and bitter pit. Variability in bitter pit may be related to factors linked to canopy position such as shade (Jackson and Sharples, 1971; Smock, 1941), which can influence fruit size (Jackson and Sharples, 1971; Marini and Barden, 1982b) transpiration (Wiersum, 1966), and cation availability to the fruit (Cline and Hanson, 1992; Marini and Barden, 1982a; Tadesse et al., 2001; Tromp and Oele, 1972; Wiersum, 1966; Wilkinson, 1968). Witney et al. (1991) increased the incidence of bitter pit 4-fold by shading 'Golden Delicious' fruiting spurs with brown paper bags. When de Freitas et al. (2013) compared fruit from shaded and nonshaded trees, fruit from shaded trees had more bitter pit and greater concentrations of calcium and magnesium. They hypothesized that shading influenced bitter pit by altering the distribution of calcium within fruit because shaded fruits had more calcium bound to cell walls. Previous reports of canopy position on bitter pit were inconsistent. For example, in England and New Zealand, fruit from the tree interior and from the lower north side of vigorous 'Cox's Orange Pippin' trees were smaller, had less red color, greater calcium concentrations, and a lower incidence of bitter pit than fruit from other canopy positions (Ferguson and Triggs, 1990; Jackson and Sharples, 1971). To the contrary, Kalcsits et al. (2019), working with 'Honeycrisp' in intensive orchards in Washington, found that fruit in the upper canopy had high calcium and low bitter pit. In two of our four experiments, bitter pit was affected by canopy position, but the effect of canopy position depended on other factors, especially FW. For example, at Aspers orchard 1, the probability of developing bitter pit was greatest for large fruit in the upper canopy on the north side of the tree. For Rock Springs in 2016, large fruit from the canopy interior had the greatest probability of developing bitter pit.

We also collected fruit from different canopy positions in a 'Honeycrisp' orchard in Fishertown, PA, in 2019 with a history of severe bitter pit. The trees were on M.7 rootstock and were very vigorous, with most terminal shoots exceeding $45 \mathrm{~cm}$. There was a high incidence of bitter pit regardless of canopy position or number of fruit per spur. For the 24 combinations of two tree sides, two canopy heights, two distances from the trunk, and three levels of fruits per spur, the number of pits per fruit ranged from 15.1 to 24.0 , and the proportion of fruit with bitter pit ranged from $63 \%$ to $88 \%$. Bitter pit severity, bitter pit incidence, and the probability of a fruit developing bitter bit were not affected significantly by any of the variables recorded for our study. This supports our previous report in which bitter pit related positively to tree vigor and terminal shoot length (Baugher et al., 2017), and tree vigor may be the most important variable influencing bitter pit.

Implications for research fruit sampling. These results can be used to improve protocols for obtaining fruit samples that better represent the population of fruit on a tree for predicting the probability that fruit will develop poststorage bitter pit. Kalcsits et al. (2019) suggested that fruit should be sampled from different canopy positions because microclimate may contribute to bitter pit development. We agree that canopy position should be used as a criterion for sampling fruit, but spur characteristics, such as fruit size, number of fruit per spur, length of bourse shoots, and number of leaves per spur, as well as crop load, should also be considered. Results from our study and others may not have broad application. Multisite studies with varying tree sizes, rootstocks, and climatic factors are needed to verify previously published data.

Implications for managing bitter pit. Results from this and previous studies can be used to modify orchard practices to minimize the incidence of bitter pit. To reduce the likelihood of spring frost and ensure moderate to heavy crops that are less prone to bitter pit, 'Honeycrisp' should be planted on excellent sites with good, cold air drainage, and frost protection should be considered. In our experiments in which the number of fruit per spur was recorded, the probability of a fruit developing bitter pit was greatest for spurs with one fruit. Commercial growers typically apply chemical thinners followed by hand-thinning to avoid multiple fruit per spur and enhance FW. Our results support previous reports in which FW related negatively to the number of fruit per spur (Black et al., 2000; Denne, 1963). Our results also indicate that the likelihood of bitter pit development increased with increasing FW (Fig. 10) and decreased with increasing numbers of fruit per spur (Fig. 11). For each additional fruit per spur, FW declined by $\approx 16 \mathrm{~g}$, and the probability of developing bitter pit decreased by $\approx 10 \%$. Therefore, one way to reduce the severity of bitter pit may be to retain two fruit per spur while hand-thinning, especially on trees with moderate to light crops. 'Honeycrisp' trees often produce large fruit, and the moderate loss of fruit size associated with multiple fruit per spur may not be economically deleterious. If hand-thinning is required to adjust crop load, and if early-season fruit size is adequate, then orchard workers may be instructed to retain more than two fruit per cluster. Workers should also be instructed to retain fruit on spurs with many leaves and long bourse shoots. At harvest, fruit from trees with low crop loads can be placed in bins designated for immediate sale.

In conclusion, our study showed that logistic regression can be used to predict the probability that individual fruit will develop bitter 
pit. Logistic regression is a powerful tool that can be used in many other types of horticultural research in which a binary response is recorded, such as seed germination, fruit set, fruit abscission, plant survival, and plant flowering. The relationship between bitter pit and FW was influenced inconsistently by canopy position. Although bitter pit was affected by the interactive effects of several variables, bitter pit was most often influenced by $\mathrm{FW}$, number of fruit per spur, and number of leaves per spur.

\section{Literature Cited}

Ahrens, W.H., D.J. Cox, and G. Budhawar. 1990. Use of the arcsine and square root transformations for subjectively determined percentage data. Weed Sci. 38:452-458, doi: 10.1017/ S0043174500056824.

Al Shoffe, Y., J.F. Nock, Y. Zhang, L.W. Zhu, and C.B. Watkins. 2019. Comparisons of mineral and nonmineral prediction methods for bitter pit in 'Honeycrisp' apples. Scientia Hort. 254:116123, doi: 10.1016/j.scienta.2019.04.073483.

Baugher, T.A., R. Marini, J.R. Schupp, and C.B. Watkins. 2017. Prediction of bitter pit in 'Honeycrisp' apples and best management implications. HortScience 52:1368-1374, doi: 10.21273/HORTSCI12266-17.

Black, B.L., M.J. Bukovac, and M. Stopar. 2000. Intraspur fruit competition and position influence fruit size at harvest and response to chemical thinning agents in spur-type 'Delicious' apple. Acta Hort. 527:119-126, doi: 10.17660/ ActaHortic.2000.527.13

Broom, F.D., G.S. Smith, D.B. Miles, and T.G.A Green. 1998. Within and between tree variability in fruit characteristics associated with bitter pit incidence of 'Braeburn' apple. J. Hort. Sci. Biotechnol. 73:555-561, doi: 10.1080/14620316. 1998.11511014.

Cheng, L. and M.M. Sazo. 2018. Why is 'Honeycrisp' so susceptible to bitter pit? Fruit Qrtly. 26(1):19-23.

Cline, J.A. and E.J. Hanson. 1992. Relative humidity around apple fruit influences its accumulation of calcium. J. Amer. Soc. Hort. Sci. 117: 542-546, doi: 10.21273/JASHS.117.4.542.

de Freitas, S.T., C.V.T. do Amarante, A.M. Dandekar, and E.J. Mitcham. 2013. Shading affects flesh calcium uptake and concentration, bitter pit incidence and other fruit traits in 'Greensleeves' apple. Scientia Hort. 161: 266-272, doi: 10.1016/j.scienta.2013.07.019.

Denne, P. 1963. Fruit development and some tree factors affecting it. N. Z. J. Bot. 13:265-294, doi: 10.1080/0028825X.1963.10428999.

Feng, F., M. Li, F. Ma, and L. Cheng. 2014. Effects of location within the tree canopy on carbohydrates, organic acids, amino acids and phenolic compounds in the fruit peel and flesh from three apple (Malus $\times$ domestica) cultivars. Hort. Res. 1:14019, doi: 10.1038/hortres.2014.19.

Ferguson, I.B. 2001. Calcium in apple fruit. Proceedings of the Washington Tree Fruit Postharvest Conference, Wenatchee, WA. 19 July 2021. <https://www.yumpu.com/en/document/ view/48220432/calcium-in-apple-fruit-2001507 postharvest-information-network $>$.

Ferguson, I.B. and C.M. Triggs. 1990. Sampling factors affecting the use of mineral analysis of apple fruit for the prediction of bitter pit. N. Z. J. Crop Hort. Sci. 18:2-3, 147-152, doi: $10.1080 / 01140671.1990 .10428086$.

Ferguson, I.B. and C.B. Watkins. 1989. Bitter pit in apple fruit. Hort. Rev. 11:289-355.
Ferguson, I.B. and C.B. Watkins. 1992. Crop load affects mineral concentrations and incidence of bitter pit in 'Cox's Orange Pippin' apple fruit. J. Amer. Soc. Hort. Sci. 117:373-376, doi 10.21273/JASHS.117.3.373.

Gönen, M. 2006. Receiver operating characteristic (ROC) curves. Proceedings of the NE SAS User Group Conference, Philadelphia, PA. 19 July 2021. <https://www.lexjansen.com/nesug/ nesug06/an/da11.pdf $>$.

Hosmer, D.W. and S.L. Lemeshow. 2000. Applied logistic regression. 2nd ed. Wiley, New York, NY.

Jackson, J.E. and R.O. Sharples. 1971. The influence of shade and within-tree position on apple fruit size, colour and storage quality. J. Hort Sci. 46:277-287, doi: 10.1080/00221589.1971. 11514408 .

Jones, H.G. and T.J. Samuelson. 1983. Calcium uptake by developing apple fruits: II. The role of spur leaves. J. Hort. Sci. 58:183-190, doi: 10.1080/00221589.1983.11515108.

Kalcsits, E., L. Mattheis, L. Giordani, M. Reid, and K. Mullin. 2019. Fruit canopy positioning affects fruit calcium and potassium concentrations, disorder incidence, and fruit quality for 'Honeycrisp' apple. Can. J. Plant Sci. 99:761-771, doi: 10.1139/cjps-2019-0017.

Kiernan, K. 2018. Insights into using the GLIMMIX procedure to model categorical outcomes with random effects. SAS Global Forum Proceedings Paper SAS2179-2018. 19 July 2021. <https:// www.sas.com/content/dam/SAS/support/en/sasglobal-forumproceedings/2018/2179-2018. pdf $>$.

Krishnaprakash, M.S., B. Aravindaprasad, C.A. Krishnaprasad, P. Narasimham, S.M. Ananthakrishma, S. Dhanaraj, and V.S. Govindarajan. 1983. Effect of apple position on the tree on maturity and quality. J. Hort. Sci. 58:31-36, doi: 10.1080/00221589.1983.11515087.

Llewelyn, R.W.M. 1968. The $\log (-\log )$ transformation in the analysis of fruit retention records. Biometrics 24:627-638, doi: 10.2307/2528322.

Marini, R.P. 2003. Approaches to analyzing experiments with factorial arrangements of treatments plus other treatments. HortScience 38:117-120, doi: 10.21273/HORTSCI.38.1.117.

Marini, R.P. and J.A. Barden. 1981. Seasonal correlations of specific leaf weight to net photosynthesis and dark respiration of apple leaves. Photosynth. Res. 2:251-258.

Marini, R.P. and J.A. Barden. 1982a. Net photosynthesis, dark respiration, transpiration, and stomatal resistance of young and mature apple trees as influenced by summer or dormant pruning. J. Amer. Soc. Hort. Sci. 107:170-174.

Marini, R.P. and J.A. Barden. 1982b. Yield, fruit size, and quality of three apple cultivars as influenced by summer or dormant pruning. J. Amer. Soc. Hort. Sci. 107:474-479.

Marini, R.P., R.E. Byers, and D.L. Sowers. 1993. Repeated applications of NAA control preharvest drop of 'Delicious' apples. J. Hort. Sci. Biotechnol. 68:247-253, doi: 10.1080/00221589. 1993.11516349.

Park, S.H., J.M. Goo, and C.H. Jo. 2004. Receiver operating characteristic (ROC) curve: Practical review for radiologists. Korean J. Radiol. 5: 11-18, doi: 10.3348/kjr.2004.5.1.11.

Perring, M.A. 1986. Incidence of bitter pit in relation to the calcium content of apples: Problems and paradoxes, a review. J. Sci. Food Agr. 37:591-606, doi: 10.1002/jsfa.2740370702.

Perring, M.A. and C.H. Jackson. 1975. The mineral composition of apples: Calcium concentration and bitter pit in relation to mean mass per apple.
J. Sci. Food Agr. 26:1493-1502, doi: 10.1002/ jsfa. 2740261008 .

Prange, R., J. Delong, D. Nichols, and P. Harrison. 2015. Effect of fruit maturity on the incidence of bitter pit, senescent breakdown, and other post-harvest disorders in 'Honeycrisp'TM apple. J. Hort. Sci. Biotechnol. 86:245-248, doi: 10.1080/14620316.2011.11512756.

Robinson, T. and S. Lopez. 2012. Crop load affects 'Honeycrisp' fruit quality more than nitrogen, potassium, or irrigation. Acta Hort., doi: 10.17660/ActaHortic.2012.940.76.

Schabenberger, O. 2005. Introducing the GLIMMIX procedure for generalized linear mixed models. SUGI 30 paper 196-30. 20 July 2021. <https:// support.sas.com/resources/papers/proceedings/ proceedings/sugi30/196-30.pdf>.

Serban, 5C. and L. Kalcsits. 2018. Altering shoot extension did not affect bitter pit incidence in 'Honeycrisp' apple. HortScience 53:1827-1834, doi: 10.21273/HORTSCI13500-18

Serra, S., R. Leisso, L. Giordani, L. Kalcsits, and S. Musacchi. 2016. Crop load influences fruit quality, nutritional balance, and return bloom in 'Honeycrisp' apple. HortScience 51:236-244, doi: 10.21273/HORTSCI.51.3.236

Shin, S. and B. Coulter. 2009. ROC analysis for the evaluation of continuous biomarkers: Existing tools and new features in $\mathrm{SAS}^{\circledR}$ 9.2. Proceedings of the 34th Annual SAS ${ }^{\circledR}$ Users Groups International Conference. 20 July 2021. <https://www. lexjansen.com/pharmasug/2009/sp/SP09.pdf>.

Smock, R.M. 1941. Studies on bitter pit of the apple. Mem. Cornell Univ. Agr. Expt. Sta. 587(234):45.

Tadesse, T., M.A. Nicholas, E.W. Hewett, and K.J. Fisher. 2001. Relative humidity around the fruit influences the mineral composition and incidence of blossom-end rot in sweet pepper fruit. J. Hort. Sci. Biotechnol. 76:9-16, doi: 10.1080/ 14620316.2001.11511319.

Torres, E., I. Recasens, G. Avila, J. Lordan, and S. Alegre. 2017. Early stage fruit analysis to detect a high risk of bitter pit in 'Golden Smoothee' Scientia Hort. 219:98-106, doi: 10.1016/j. scienta.2017.03.003.

Tromp, J. 1974. The effect of temperature on growth and mineral nutrition of fruits of apple, with special reference to calcium. Physiol. Plant. 33: 87-93, doi: 10.1111/j.1399-3054.1975.tb03771.x.

Tromp, J. and J. Oele. 1972. Shoot growth and mineral composition of leaves and fruits of apple as affected by relative air humidity. Physiol. Plant. 27:253-258, doi: 10.1111/j.13996023054.1972. tb03610.x.

Tustin, D., P. Hirst, and I. Warrington. 1988. Influence of orientation and position of fruiting laterals on canopy light penetration, yield, and fruit quality of 'Granny Smith' apple. J. Amer. Soc. Hort. Sci. 113:693-699.

Volz, R.K., I.B. Ferguson, E.W. Hewett, and D.J. Woolley. 1994. Wood age and leaf area influence fruit size and mineral composition of apple fruit. J. Hort. Sci. 69:385-395, doi: 10.1080 14620316.1994.11516468.

Warton, D.I. and F.K.C. Hui. 2011. The arcsine is asinine: The analysis of proportions in ecology. Ecology 92:3-10, doi: 10.1890/10-0340.1.

Wiersum, L.K. 1966. Calcium content of fruits and storage tissues in relation to the mode of water supply. Acta Bot. Neerl. 15:406-418. doi 10.1111/j.1438-8677.1966.tb00240.x614.

Wilkinson, B.G. 1968. Mineral composition of apples IX: Uptake of calcium by the fruit. J. Sci. Food Agr. 19:646-647, doi: 10.1002/jsfa.2740191107.

Witney, G.W., M.M. Kushad, and J.A. Barden. 1991. Induction of bitter pit in apple. Scientia Hort. 47:173-176, doi: 10.1016/0304-4238(91) 90039-2. 